\title{
Determination of permissible defect size for solid axles loaded under fully-reversed rotating bending
}

\author{
A.R. Torabi ${ }^{a^{*}}$ and M.R.M. Aliha
} \author{
Tehran-Iran

\section{A R T I C L E I N F O} \\ Article history: \\ Received January 15, 2013 \\ Received in Revised form \\ March, 26, 2013 \\ Accepted 18 June 2013 \\ Available online \\ 29 June 2013 \\ Keywords: \\ Defect \\ Crack growth \\ C35 steel \\ Fatigue \\ Four-point bending
}

${ }^{a}$ Fracture Research Laboratory, Faculty of New Science and Technologies, University of Tehran, P.O. Box 13741-4395, Tehran, Iran

${ }^{b}$ Welding and Joining Research Center, School of Industrial Engineering, Iran University of Science and Technology (IUST), Narmak, 16846-13114,

Fracture Mechanics

\begin{abstract}
A B S T R A C T
The aim of the present work was to develop a guideline for approving the railway axles made of C35 steel and containing surface and/or in-body defects after manufacturing. First, several through and part-through circular cracks were modeled on the surface and in the body of the axle at its critical cross-section. Then, the permissible size of such cracks was determined by using the fracture mechanics. To verify the validity of the guideline, the theoretical result for the semi-circular surface crack was compared with the allowable size prescribed by the international railway standard. A very good agreement was found to exist between the predicted and the standard values.
\end{abstract}

\section{Introduction}

Railway axle is a safety critical component in the train load-carrying system that it is always designed to be in service typically up to 30 years. This component transmits the vehicle weight to the wheels and due to its rotation; it is subjected to fatigue loading conditions. The alternating stresses applied to the axle result in fatigue crack initiation from the axle surface and then crack growth till final abrupt fracture.

The fatigue failure of railway axles has been frequently investigated by the researchers as a common cause of derailment both theoretically and experimentally. The fatigue failure of a railway axle in Turkey railway transportation system has been theoretically studied in Bayrakter et al. (2010). The influences of surface defects and inclusions on the life of a failed railway axle has been studied in

* Corresponding author. Tel.: +98 21-61 118 572, Fax: +98 21-88 617087

E-mail addresses: a torabi@ut.ac.ir (A.R. Torabi)

(C) 2013 Growing Science Ltd. All rights reserved.

doi: $10.5267 /$ j.esm.2013.06.002 
Alihosseini and Dehghani (2010) and revealed that the axle has been very sensitive to the surface machining scratches even if they are very small. Makino et al. (2011) reviewed the fatigue damage tolerance of high-speed railway axles in Japan railway network and the crack growth behavior of an induction-hardened axle has been assessed based on the fracture mechanics. The fracture mechanics has also been utilized by Beretta et al. (2005) for investigating the fatigue fracture of railway axles. Beretta and coworkers (2011) have also investigated corrosion-fatigue in full scale railway axle in A1T mild steel using three-point rotating bend loading with the artificial rainwater as corrosive environment. Moreover, basic fatigue crack growth data both in the range of stable crack propagation and near the threshold have been experimentally determined in Luke et al. (2005) for the heat-treated railway axle steels under constant and variable amplitude loading at corresponding stress ratios. Other technical reports (e.g. Zerbst et al. 2005 and 2011, Madia. et al. 2008, Luke et al. 2010, Linhart and Cerny 2011, Beretta and Carboni 2011) dealing with investigating the fatigue failure of railway axles can be referred which most of the failures start from the positions of stress concentrations such as notches, defects, cracks and scratches.

After manufacturing, various types of stress concentrators such as metallic and non-metallic inclusions, voids, defects and scratches are sometimes recognized in the axle that some of these discontinuities may lead to premature failure. Hence, derailment and other possible events may occur. Now days, beside experience, the criticality of such pre-existing defects can be accurately determined thanks to the fracture mechanics as the main knowledge in damage tolerant design. Since cracks having sizes larger than permitted would propagate and lead to axle premature fatigue failure, it is necessary to check the axle health prior to its service to see if the size of likely detected defects is within the allowable range.

In this work, the attempt was made to determine the permissible defects size for the railway axles. The idea to do this work was started from the point that the permissible defect size prescribed by the international railway standard UIC 811-1 (1983) is unique and it is not clear enough that whether or not it is for part-through surface cracks at the critical section of the axle. If yes, what about the axles containing no surface defect and having instead flaws located completely in the axle body and behave as through cracks? To answer these important questions, first, a part-through semi-circular surface crack and several part-through and through circular cracks were modeled in the axle critical section. Then, the permissible size of such cracks was determined in various positions between the axle surface and its center by comparing the value of the stress intensity factors with the value of the fatigue crack propagation threshold of the material as a possible criterion. To evaluate the computations, the permissible size obtained theoretically for the semi-circular crack was compared with that suggested by the international railway standard UIC 811-1 (1983). The results showed that the determined value was in a very good consistency with the standard value. Although there were not general reference standard values of allowable size for through defects, the presented approach and the obtained results could be satisfactorily trusted because all of the computations (including for semi-circular crack) were carried out in a same manner.

\section{Axel specifications}

\subsection{Geometry and loading}

A detailed view of the studied axle is shown in Fig. 1 (given from Iran railway research centerIRRC, 2000). As seen in this figure, the solid shaft has been made enbloc and its cross-section is circular. In several locations on the shaft, fillets with different radii are seen which act as the stress concentrators. The total vehicle weight was $225 \mathrm{kN}$ and it was equally applied to the shaft in two symmetric positions ( $112.5 \mathrm{kN}$ concentrated load for each wheel location with diameter of $200 \mathrm{~mm}$ in Fig. 1). The axle was constrained with two bearings at its right and left ends and hence, the shaft was subjected to four-point rotating bending. 


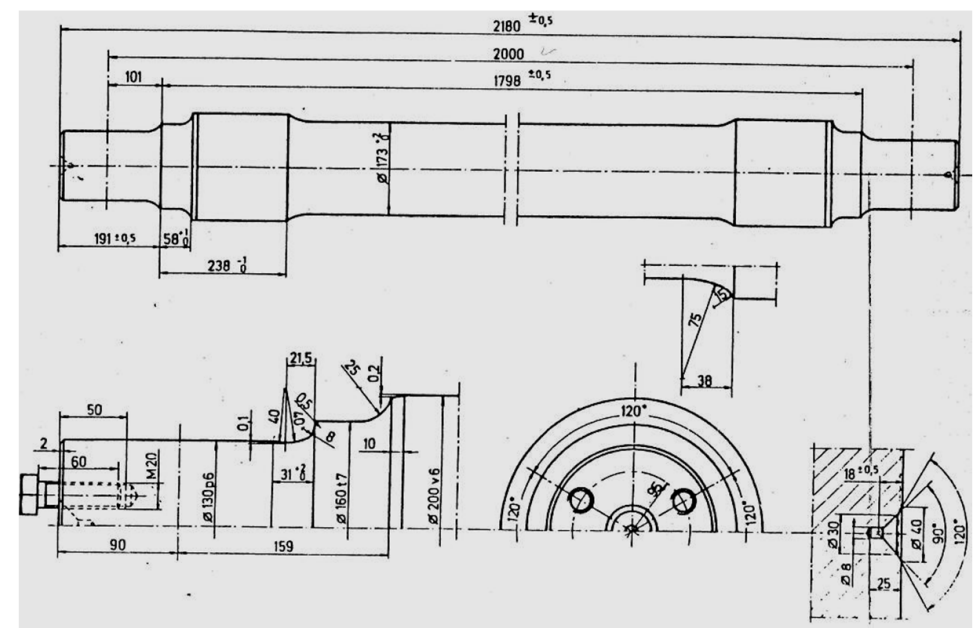

Fig. 1. Detail of the axle geometry (IRRC, 2000)

\subsection{Material}

The material used for fabricating the axle was carbon steel C35. The chemical composition and the general mechanical properties of the material are presented in Tables 1 and 2, respectively.

Table 1. Chemical composition of the material

\begin{tabular}{ccccccc} 
Component & $\mathrm{C}$ & $\mathrm{Mn}$ & $\mathrm{Si}$ & $\mathrm{Ni}$ & $\mathrm{Cr}$ & Others \\
\hline Content $(\%)$ & 0.37 & 1.12 & 0.46 & 0.3 & 0.3 & 0.08 \\
\hline
\end{tabular}

Table 2. General mechanical properties of the material

\begin{tabular}{ccccccc}
\hline Property & $\begin{array}{c}\text { Yield strength } \\
(\mathrm{MPa})\end{array}$ & $\begin{array}{c}\text { Ultimate tensile } \\
\text { strength }(\mathrm{MPa})\end{array}$ & $\begin{array}{c}\text { Elongation } \\
(\%)\end{array}$ & $\begin{array}{c}\text { Elastic } \\
\text { modulus }(\mathrm{GPa})\end{array}$ & $\begin{array}{c}\text { Poisson's } \\
\text { ratio }\end{array}$ & $\begin{array}{c}\text { Hardness } \\
(\mathrm{HB})\end{array}$ \\
\hline Value & 320 & 520 & 22 & 203 & 0.3 & 175 \\
\hline
\end{tabular}

\section{Stress analysis}

In order to determine the stress distribution in the shaft, first, a 3-D model was created for the axle according to its geometry presented in Fig. 1. The model is shown in Fig. 2.

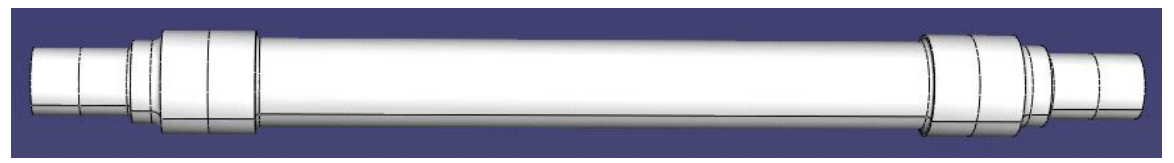

Fig. 2. A 3-D model of the axle

The model was meshed; the loading and boundary conditions were applied and the finite element linear elastic stress analysis was performed by using the commercial code ABAQUS. A total number of 40000 quadratic elements were used in the model. A large number of elements were utilized in the vicinity of fillets because of existing high stress gradients. Figs. 3 and 4 reveal the meshed axle after loading and the longitudinal stress distribution in the axle, respectively.

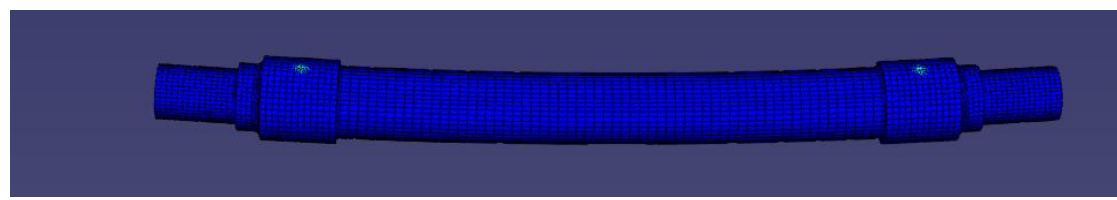

Fig. 3. The meshed axle after loading 


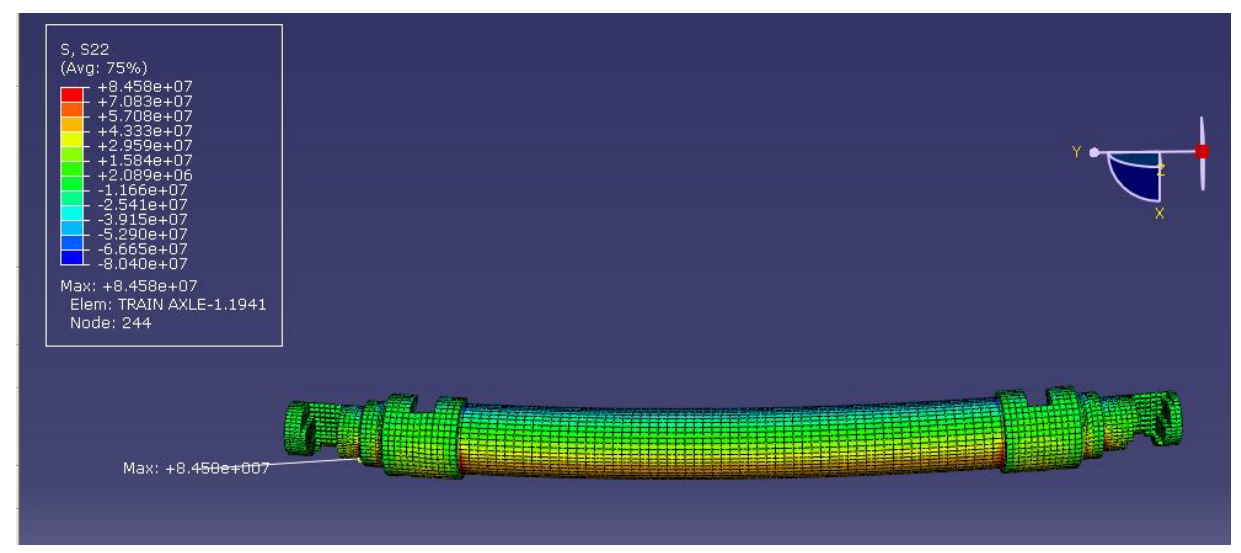

Fig. 4. The longitudinal stress distribution in the axle

Note that the locations of the applied loads and also the bearing positions are locally removed after analysis to avoid misunderstanding about the position of the maximum stress (those locations experience high local stresses due to concentrated loads applied). Fig. 5 shows clearly that the maximum Von-Mises stress of about $80 \mathrm{MPa}$ occurs on the shaft surface at the first fillet near to the bearings location. Since the dominant stress component in the shaft is longitudinal (due to bending), the maximum values of the longitudinal and Von-Mises stresses are very close together (about 84 and $80 \mathrm{MPa}$, respectively).

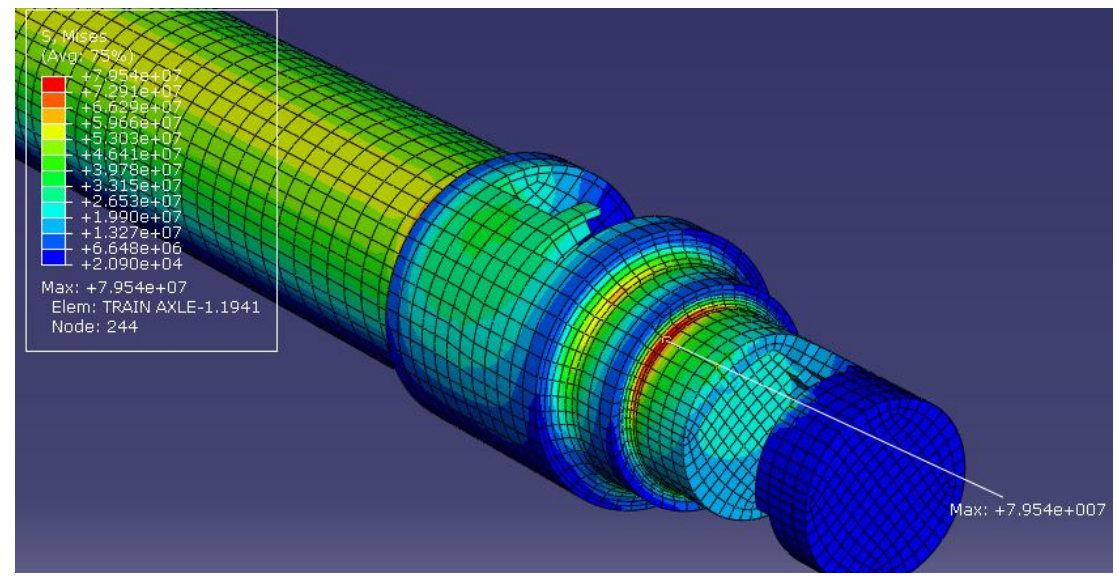

Fig. 5. Von-Misses stress distribution in the axle

A comparison of the value of maximum Von-Mises stress with the material yield strength (presented in Table 2) revealed that the material strength is four times larger than the maximum stress demonstrating no plastic deformation in the axle.In the next section, the stress distribution obtained above is utilized to compute the stress intensity factors (SIFs) for several defects located in different positions at the critical cross-section of axle and to determine the allowable size for them.

\section{Determination of permissible defects size}

\subsection{Part-through semi-circular crack}

The international railway standard UIC 811-1 (1983) prescribes permissible defects size of maximum $3 \mathrm{~mm}$ in production of road axles. The UIC prescription is not clear enough for considering the influence of cracks at the critical region of the railway axle. Also, it is not stated in this standard that the permissible size is for what kinds of cracks (e.g. part-through or through etc.). Therefore, first, a part-through semi-circular surface crack of $3 \mathrm{~mm}$ radius was modeled in the shaft at its critical section and the maximum stress intensity factors (SIFs) were computed by using the finite element 
(FE) method under the applied load. Finally, comparing the SIFs with the value of the fatigue crack propagation threshold of the material gave rise to judge preliminarily about the possibility of growing the defect as elaborated below. Fig. 6 shows the cross-section of the axle at its critical region (i.e. the location of the maximum stress) containing several semi-circular surface defects of different radii modeled in the FE software.

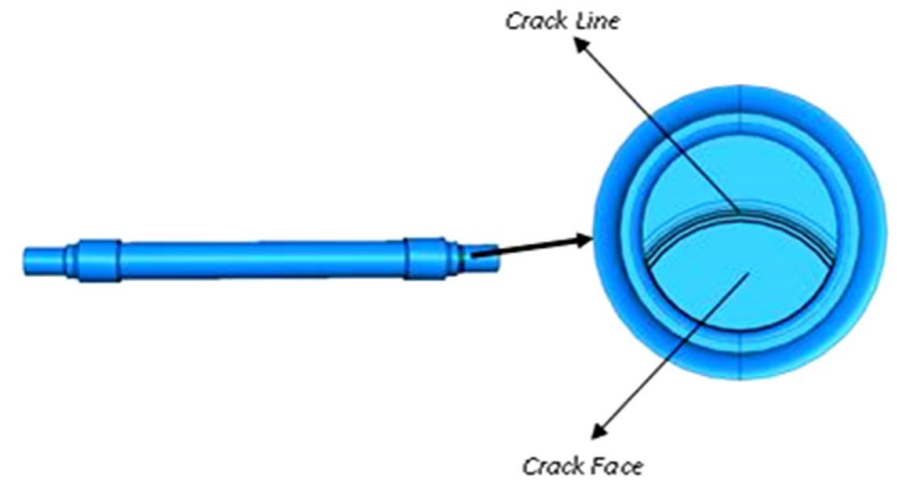

Fig. 6. The axle critical cross-section containing several semi-circular surface defects of different radii

To compute the SIFs more accurately, a large number of elements were created at the vicinity of the crack front because of high stress gradient. Fig. 7 depicts a mesh pattern around the crack front.

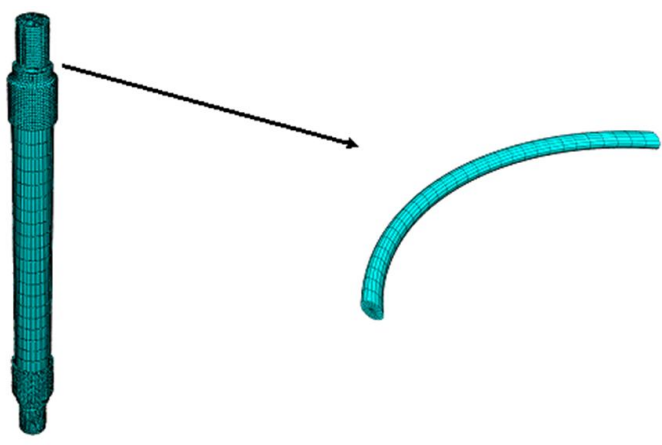

(a)

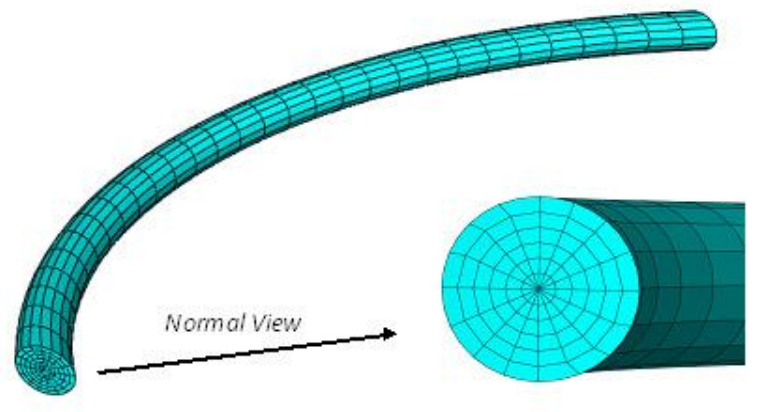

(b)

Fig. 7. A FE mesh pattern around the crack front

The modes I, II and III SIFs (i.e. $K_{\mathrm{I}}, K_{\mathrm{II}}$ and $K_{\mathrm{III}}$ ) were calculated for the modeled crack (i.e. the crack with $3 \mathrm{~mm}$ radius) using the fracture toolbox of ABAQUS. It was found that $K_{\text {III }}$ was zero and $K_{\text {II }}$ was about $6 \%$ of $K_{\mathrm{I}}$ demonstrating mode I dominant loading conditions. Thus, the contribution of mode II crack deformation was neglected and the loading was assumed to be pure mode I (this assumption is illustratively demonstrated in the section 5 of the present paper for a broken defective axle). The value of $K_{\mathrm{I}}$ for the crack was obtained to be approximately equal to $6.15 \mathrm{MPa} \mathrm{m}^{0.5}$. This value is almost the same with the value of the fatigue crack propagation threshold $\left(\Delta K_{t h}\right)$ of the $\mathrm{C} 35$ steel reported by Iran railway research center $(2000)$ to be equal to $6 \mathrm{MPa} \mathrm{m}^{0.5}$. Note that $\Delta K_{t h}$ value presented in this report has been determined by conducting the standard fatigue crack growth test according to the ASTM E647-95 (1995). Consequently, the crack radii larger than about $3 \mathrm{~mm}$ will result in $\Delta K_{I}>\Delta K_{t h}$ and hence, the defect may propagate under fatigue loading. In addition to $\Delta K_{t h}$, another important factor which is required to evaluate the growth of initial defects under mode I loading conditions is the value of tensile stress at the critical distance $r_{c}$ from the crack front. $r_{c}$ is determined from the following equation suggested by El Haddad et al. (1979)::

$r_{c}=\frac{1}{2 \pi}\left(\frac{\Delta K_{t h}}{S_{e}^{*}}\right)^{2}$ 
where $S_{e}^{*}$ is the modified fatigue limit of the material. The critical distance is assumed to be the material property. According to El Haddad et al. (1979), crack would propagate under fatigue loading if the value of tensile stress at the critical distance $r_{c}$ from the crack front attains the modified fatigue limit $\left(S_{e}^{*}\right)$ of the material (see also Taylor, 2005). The material endurance limit $S_{e}$ could be initially assumed to be approximately equal to the half of the ultimate tensile strength $S_{u}\left(S_{e}=0.5 S_{u}=260\right.$ $\mathrm{MPa}$ ) as prescribed in Shigley et al. (2003) for steels with $S_{u}$ lower than $1400 \mathrm{MPa}$ (this initial assumption was made due to the fact that the dominant stress component in bending loading is tensile-compressive like that exists in uni-axial tension-compression). This value (i.e. $260 \mathrm{MPa}$ ) agrees well with the endurance limit of C35 steel reported in the literature (see for instance Nasr, 2010). To determine the modified fatigue limit, $S_{e}$ must be multiplied with several correction factors such as surface factor, scale factor, reliability factor etc. described in Shigley et al. (2003). Finally, the modified fatigue limit for the axle steel was calculated to be equal to $152 \mathrm{MPa}$. This value is satisfactorily consistent with the experimental value of the endurance limit (i.e. $161 \mathrm{MPa}$ ) resulted from the actual fully-reversed rotating bending S-N diagram for the investigated material. The value of $r_{c}$ for the investigated axle was calculated to be approximately $0.24 \mathrm{~mm}$ and the Von-Mises stress at this distance was obtained via $\mathrm{FE}$ analysis to be about $186 \mathrm{MPa}$ which is sufficiently greater than $S_{e}^{*}$. From the above statements, it can be concluded that the $3 \mathrm{~mm}$ semi-circular crack at the critical section of the axle would be propagated and the prescription of UIC is interestingly consistent with the results obtained from the fracture mechanics. An important question still remains; should the same criterion suggested by UIC (i.e. permissible crack size of $3 \mathrm{~mm}$ ) always be applied for all kinds of defects with different locations at the axle critical region? The answer to this question can be found in the next subsection.

\subsection{Through and part-through circular cracks}

In order to answer the above question appropriately, first several through and part-through cracks of circular shape having arbitrarily different radii were modeled in various positions between the axle surface and center at the axle critical section. Then, the maximum values of the mode I SIF $\left(K_{\mathrm{I}}^{\max }\right)$ were numerically computed by FE method for each crack. Finally, by following the trial-and-error procedure, each crack size was modified until the $K_{\mathrm{I}}^{\max }$ attains $\Delta K_{t h}$. The obtained radii may be the permissible sizes for through and part-through circular defects. The initially obtained permissible sizes should be finally checked against the value of tensile stress at the critical distance. Those cracks pass both the conditions above would be propagating. Table 3 presents the positions of circular defects and their computational values of allowable radii in the studied railway axle.

Table 3. The computational values of allowable radii and the positions of circular defects in the studied railway axle

\begin{tabular}{|c|c|}
\hline Distance between the centers of crack and axle $(\mathrm{mm})$ & Permissible radius $(\mathrm{mm})$ \\
\hline $65.4^{*}$ & $\sim 3$ \\
\hline 60.5 & 14 \\
\hline 55.5 & 46 \\
\hline 51.0 & 55.8 \\
\hline 46.6 & 62.1 \\
\hline 42.2 & 69.5 \\
\hline 37.8 & 75 \\
\hline 33.5 & 83 \\
\hline 29.1 & 86 \\
\hline 24.8 & 92 \\
\hline 20.4 & 99 \\
\hline 16.0 & 105 \\
\hline 11.7 & 112.5 \\
\hline 7.4 & 118 \\
\hline $0^{* *}$ & Any possible value \\
\hline
\end{tabular}




\section{Analysis of fatigue crack growth}

Although the railway axles containing growing defects are usually rejected after manufacturing, they can be used in a controlled manner if and only if the fatigue life of the defective axles could be accurately estimated (this is directly related to the policy of the manufacturing company). Moreover, to determine the inspection intervals for axles produced, fatigue crack propagation analysis should be performed. A general stable fatigue crack growth model under mixed mode I/II loading can be written as $d a / d N=B(\Delta S)^{m}$ (Sih, 1991) or $d a / d N=B^{*}\left(\Delta K_{e f f}\right)^{m^{*}}$ (Zhang and Fatemi, 2010) where the parameters $a$ and $N$ are the crack length and the number of cycles, respectively. The coefficients $B$ and $B^{*}$ and the exponents $m$ and $m^{*}$ can be found by test for mixed mode (Sih 1991, Zhang and

Fatemi, 2010). $K_{\text {eff }}$ is the effective stress intensity factor typically equal to $K_{\text {eff }}=\sqrt{K_{I}^{2}+K_{I I}{ }^{2}}$. As previously mentioned, the value of $K_{\mathrm{II}}$ was obtained for the axle equal to about $6 \% K_{\mathrm{I}}$. This means that $K_{\text {eff }}=1.0017 K_{I}$ which is approximately equal to $K_{\mathrm{I}}$. Therefore, the mixed mode I/II fatigue crack propagation models can be accurately reduced to the pure mode I condition. For estimating the fatigue life of the defective axle containing a growing defect under mode I loading conditions and also, for determining the inspection intervals for the axles produced, the well-known Paris-Erdogan fatigue crack growth model presented by Paris and Erdogan, (1963) as:

$$
d a / d N=C(\Delta K)^{n}=C\left(K_{\max }-K_{\min }\right)^{n}
$$

can be utilized. This model in its original form has been successfully employed by Alihosseini and Dehghani (2010) for the life prediction of a railway axle. The parameters $C$ and $n$ could be obtained for the material by conducting standard fracture tests like that suggested in ASTM E647-95 (1995). The values of $C$ and $n$ for the material of the present axel under the stress ratio $R=-1$ were obtained according to ASTM E647-95 (1995) equal to $6.87 \times 10^{-12}(\mathrm{~m} / \mathrm{cycle})$ and 3.0, respectively. The cycles to failure for the axle could be calculated as follows,

$$
N_{f}=\int_{N=0}^{N_{f}} d N=\int_{a=a_{0}}^{a_{f}} \frac{d a}{6.87 \times 10^{-12}\left(K_{\max }\right)^{3.0}}
$$

The parameters $a_{0}$ and $a_{f}$ are the initial and the critical crack sizes, respectively. The critical crack size (i.e. the crack size at fracture) can simply be computed by knowing the material fracture toughness. Note that $K_{\max }$ clearly indicates that the stress intensity factor varies on the crack border and therefore has a maximum. Numerical calculations showed that $K_{\max }$ obtained at the intersection point of the two circles of the crack profile and the axle cross-section. This result has been previously obtained by Carpinteri and Brighenti (1996). As seen in Eq. (3), the dependency of $K$ on $a$ must be cleared in order to compute the integral. Some closed-form expressions have been presented in Carpinteri et al. $(1998,2006)$ to calculate the SIFs for surface flaws of generally semi-elliptic features (including in reduced case the semi-circular cracks) in cylindrical shafts under rotary bending. Therefore, one can utilize the same approach presented by Carpinteri et al. (1998) in order to correlate a closed-form expression for $K_{\max }$ of the present axle in terms of the crack radius $a$.

\section{Discussion}

Inevitable defects, inclusions and scratches may be introduced in the engineering components during a few manufacturing processes that some of them can be dangerous if the component is subjected to fatigue loading. These discontinuities play the role of a stress raiser and concentrate stress around them. Under fluctuating stresses, fatigue cracks can be initiated from the place of the stress raisers and propagated till final fracture. 
The railway axles produced in Iran have been found during 30 past years to be defective, mostly contain through and part-through spherical gaseous voids. Unfortunately, due to lake of a comprehensive standard or guideline to approve the axles containing surface and/or in-body defects, the axles containing any defects located everywhere in them and larger than uniquely permitted by UIC standard (1983) have already been rejected by the quality control (QC) part of the manufacturing companies. By taking this conservative strategy into account, the companies experienced a large financial loss due to a large number of product rejections. Thus, they attempted to prevent it by developing an extensive in-house standard. For this purpose, extensive analyzes were performed in the present study to determine the permissible size of defects in different locations between the axle surface and center. Such analyzes were conducted based on the fracture mechanics which is an advanced engineering tool in the context of damage tolerant design. Since the axles are subjected to four-point fully-reversed fatigue loading, the fatigue crack propagation threshold of the material was considered in conjunction with the stress condition at the critical distance as a governing parameter in the recognition of the dangerous defects. As seen in Table 3, the size of the allowable defects enhances as the center of the defect approaches the axle center. This is because, the far-field bending stress influencing the defect decreases as the defect center approaches the axle neutral axis. Hence, the stress intensity factor (SIF) decreases dramatically and $K_{\mathrm{I}}^{\max }$ reaches $\Delta K_{t h}$ for larger defect sizes. Note that some of the data presented in Table 3 may not be occurred in practical applications. Nevertheless, they are presented with the aim to cover the entire cross-section.

It is necessary to highlight that the only available data for verifying the validity of our approach was the general guideline of UIC which was found in this work by fracture mechanics to be prescribed for surface cracks at the axle critical section. Based on this important finding, the allowable size for several circular cracks located in different places between the axle surface and center was determined thanks to the fracture mechanics. Although comprehensive approved data of permissible defect size was not available for the present railway axle either in the standards or in the literature, the authors suggests the fracture mechanics approach (like that presented in the present manuscript) for this purpose because it was partially validated at least for part-through surface cracks and hence seems to be valid for other types of cracks. A failure evidence (an unpublished research work performed in the Iran railway research center (IRRC)) in year 2000 has demonstrated that a same railway axle containing a part-through semi-circular surface crack at its critical section with the radius slightly greater than permissible standard value $(3.5 \mathrm{~mm})$ has experienced a premature failure demonstrating again the validity of the present calculations. Fig. 8 shows a fracture surface of the above mentioned railway axle.

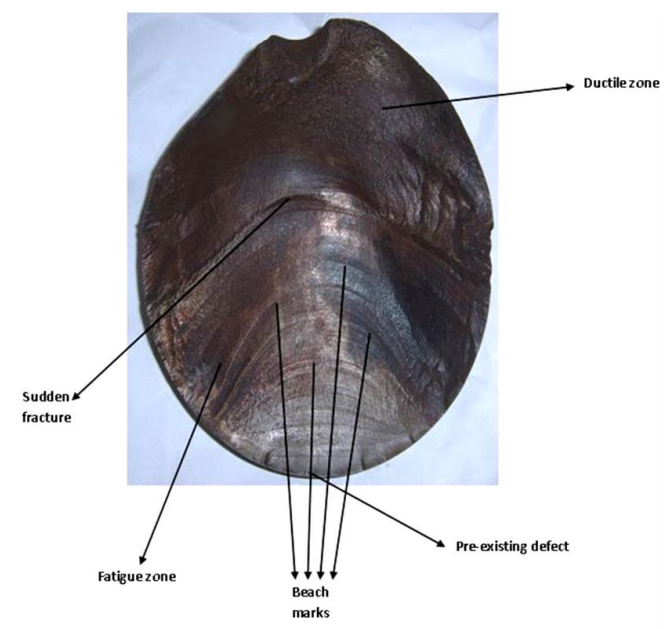

Fig. 8. The fracture surface of the axle containing a part-through semi-circular surface crack at its critical section with the radius equal to $3.5 \mathrm{~mm}$ 
As seen from Fig. 8, the fatigue beach marks move along the vertical diameter with almost no right or left deviations. This means that the role of mode II deformation is negligible and thus, the simplification of the problem to pure mode I condition is completely justifiable. Moreover, the infinite life of numerous axles having pre-existing surface defects of size less than $3 \mathrm{~mm}$ at their critical sections reported by Iran railway research center confirms clearly the validity of the calculations.

It is worth mentioning that the permissible sizes presented in this paper (see Table 3 ) are valid only for the defects having circular cross-section. For those with non-circular cross-sections, similar modeling and calculations are required. It should be finally highlighted that the main advantage of the presented approach is that the axles having defects in any places in their cross-section (detected commonly by non-destructive techniques (NDT)) can be separately checked against their corresponding allowable defect size and judged about their rejection or approve.

\section{Conclusions}

The concluding remarks of the present research are:

1- A relatively extensive guideline was developed based on the fracture mechanics for making reliable decision about rejection and approve of the railway axles containing pre-existing defects.

2- The pre-existing part-through semi-circular surface defects at the axle critical section with the size larger than $3 \mathrm{~mm}$ were analytically revealed to be growing because their $\Delta K$ were greater than the material fatigue crack propagation threshold $\Delta K_{t h}$ and also the values of tensile stress at the critical distance exceeded the modified fatigue limit of the material.

3 - The size of the allowable defects increases as the circular defect center approaches the axle center. This is because, the far-field bending stress influencing the defect decreases as the defect center approaches the axle neutral axis and hence, the stress intensity factors (SIF) decreases dramatically.

4- Neglecting the small contribution of mode II crack deformation was resulted in very well permissible defect size prediction. The mixed mode models for fatigue crack propagation threshold would be needed if $K_{\text {II }}$ becomes considerable (e.g. Sih 1991, Orringer 1992, Zhang \& Fatemi, 2010).

\section{Acknowledgement}

The authors would like to thank Dr. Sadat-Hosseini (the managing director of the Iran railway research center (IRRC)) for supporting this research. Also, Mr. Eng. Saharkhiz (the director of IRRC) is warmly acknowledged for his aid in preparing the technical data. This work was done under the research contract of number $23 \mathrm{~S} / 8798$.

\section{References}

Alihosseini, H., \& Dehghani, K. (2010). Modeling and failure analysis of a broken railway axle: Effects of surface defects and inclusions. Journal of Failure Analysis and Prevention, 10(3), 233239.

ASTM standards, E647-95 (1995). Standard test method for measurement of fatigue crack growth rates.

Bayraktar, M., Tahrali, N., \& Guclu, R. (2010). Reliability and fatigue life evaluation of railway axles. Journal of mechanical science and technology, 24(3), 671-679.

Beretta, S., Ghidini, A., \& Lombardo, F. (2005). Fracture mechanics and scale effects in the fatigue of railway axles. Engineering fracture mechanics, 72(2), 195-208. 
Beretta, S., Carboni, M., Conte, A. L., Regazzi, D., Trasatti, S., \& Rizzi, M. (2011). Crack growth studies in railway axles under corrosion fatigue: Full-scale experiments and model validation. Procedia Engineering, 10, 3650-3655.

Beretta, S., \& Carboni, M. (2011). Variable amplitude fatigue crack growth in a mild steel for railway axles: experiments and predictive models. Engineering Fracture Mechanics, 78(5), 848-862.

Carpinteri, A., \& Brighenti, R. (1996). Part-through cracks in round bars under cyclic combined axial and bending loading. International journal of fatigue, 18(1), 33-39.

Carpinteri, A., Brighenti, R., \& Spagnoli, A. (1998). Surface flaws in cylindrical shafts under rotary bending. Fatigue \& fracture of engineering materials \& structures, 21(9), 1027-1035.

Carpinteri, A., Brighenti, R., \& Vantadori, S. (2006). Surface cracks in notched round bars under cyclic tension and bending. International journal of fatigue, 28(3), 251-260.

El Haddad, M. H., Topper, T. H., \& Smith, K. N. (1979). Prediction of non propagating cracks. Engineering Fracture Mechanics, 11(3), 573-584.

International railway standards, Standard for quality control in production of road axel. UIC 811-1 (1983).

Linhart, V., \& Černý, I. (2011). An effect of strength of railway axle steels on fatigue resistance under press fit. Engineering Fracture Mechanics, 78(5), 731-741.

Luke, M., Varfolomeev, I., Lütkepohl, K., \& Esderts, A. (2010). Fracture mechanics assessment of railway axles: experimental characterization and computation. Engineering Failure Analysis, 17(3), 617-623.

Luke, M., Varfolomeev, I., Lütkepohl, K., \& Esderts, A. (2011). Fatigue crack growth in railway axles: assessment concept and validation tests. Engineering Fracture Mechanics, 78(5), 714-730.

Madia, M., Beretta, S., \& Zerbst, U. (2008). An investigation on the influence of rotary bending and press fitting on stress intensity factors and fatigue crack growth in railway axles. Engineering Fracture Mechanics, 75(8), 1906-1920.

Makino, T., Kato, T., \& Hirakawa, K. (2011). Review of the fatigue damage tolerance of high-speed railway axles in Japan. Engineering Fracture Mechanics, 78(5), 810-825.

Nasr, A., Nadot, Y., Bouraoui, C., Fathallah, R., \& Jouiad, M. (2010). Fatigue initiation in C35 steel: Influence of loading and defect. International Journal of Fatigue, 32(4), 780-787.

Orringer, O., Orkisz, J., \& Świderski, Z. (1992). Residual Stress in Rails: Field experience and test results (Vol. 1). Springer.

Paris, P. C., \& Erdogan, F. (1963). A critical analysis of crack propagation laws. Journal of Basic Engineering, 85, 528.

Shigley, J. E., Mischke, C. R., Budynas, R. G., Liu, X., \& Gao, Z. (1989). Mechanical engineering design (Vol. 89). New York: McGraw-Hill.

Sih, G. C. (1991). Mechanics of fracture initiation and propagation: surface and volume energy density applied as failure criterion. Kluwer Academic.

Taylor, D. (2005). Analysis of fatigue failures in components using the theory of critical distances. Engineering Failure Analysis, 12(6), 906-914.

Technical data for Iran railway materials, Iran railway research center (IRRC), Iran (2000).

Zerbst, U., Mädler, K., \& Hintze, H. (2005). Fracture mechanics in railway applications-an overview. Engineering Fracture Mechanics, 72(2), 163-194.

Zerbst, U., Schödel, M., \& Beier, H. T. (2011). Parameters affecting the damage tolerance behaviour of railway axles. Engineering Fracture Mechanics, 78(5), 793-809.

Zhang, H., \& Fatemi, A. (2010). Short fatigue crack growth behavior under mixed-mode loading. International journal of fracture, 165(1), 1-19. 